\title{
About HER2 monitoring using liquid biopsies in patients with gastric cancer
}

\author{
Arnaud Uguen ${ }^{1,2,3,4}$
}

Received: 21 January 2017/ Accepted: 16 March 2017/Published online: 29 March 2017

(C) The International Gastric Cancer Association and The Japanese Gastric Cancer Association 2017

To the Editor,

Shoda et al. recently reported that they monitored the HER 2 copy number status of circulating tumor DNA in patients with gastric cancer by droplet digital PCR [1]. Preoperative $H E R 2$ tumor status based on tumor samples was found to be well correlated with the HER2 plasma ratio, albeit with some discrepant results. In the postoperative follow-up, 7/13 cases presented high plasma HER2 ratios despite having an initial HER2-negative status. The authors concluded that analyzing the HER2 ratio in circulating DNA permits the detection of a HER2-positive conversion and facilitates the identification of alternative treatment choices in initially HER2-negative patients [1]. Here, we comment on the relevance of their HER2 ratio and potential alternative methods of monitoring HER2 status in liquid biopsies.

HER2 status must be checked in patients with advanced gastric cancer to determine if trastuzumab anti-HER2 protein targeted therapy is applicable. The first-line test is immunohistochemistry, to distinguish between tumors with major HER2 overexpression (score 3+), which can be treated with trastuzumab, and tumors with no or a low level of expression (score 0 or $1+$ ), which cannot. In equivocal

This comment refers to the article available at doi:10.1007/s10120016-0599-z.

\footnotetext{
Arnaud Uguen

arnaud.uguen@chu-brest.fr

Department of Pathology, CHRU Brest, 29220 Brest, France

Inserm, U1078, 29200 Brest, France

3 European University of Brittany, Brittany, France

4 Department of Pathology, University Hospital Morvan, 5, Avenue Foch, 29609 Brest, France
}

cases of HER2 protein overexpression (score 2+), in situ hybridization analyses are required to identify HER2-amplified cancers [i.e., those with a HER2(17q12)/chromosome 17 ratio $>2$ or with clusters of HER2 signals] that can be treated with trastuzumab. Thus, it is worth determining both the HER2 expression level and the HER2(17q12)/ chromosome 17 ratio in order to establish HER2 status and identify appropriate treatment choices.

The RPPH1 reference gene chosen by Shoda et al. is not located on chromosome 17 but on chromosome 14 (14q11.2) [1]. Given that gastric cancer can involve chromosomal imbalances, notably in chromosomes 17 and 14, elevation of the HER2/RPPHI ratio (i.e., the 17q12/ $14 \mathrm{q} 11.2$ ratio) could also reflect chromosome 17 polysomy or a loss of the RPPHI locus on chromosome 14, not just HER2 amplification [2]. We believe that it would be more appropriate to use a reference gene located on chromosome 17 instead of RPPH1 to check for HER2 amplification, as performed in in situ hybridization tests and in liquid biopsies from patients with breast cancers [3].

An analysis of circulating DNA will not reflect the level of expression of the HER2 protein. An increased copy number of a given gene may not be correlated with increased expression of the corresponding protein, which is a prerequisite for the corresponding targeted therapy to be efficient. An alternative liquid biopsy method of monitoring patients with advanced gastric cancer could involve searching for circulating tumor cells rather than circulating tumor DNA. Highly sensitive methods are now available to detect and isolate these rare cells in blood samples, and HER2 protein expression analyses of these cells could be performed using immunocytochemistry and in situ hybridization methods $[4,5]$.

We agree with Shoda et al. that liquid biopsies offer new and interesting opportunities to monitor tumor 
development in patients with gastric and other cancers according to a personalized medicine strategy. Further studies are needed to compare the advantages and drawbacks of circulating tumor DNA analysis to those of circulating tumor cell analysis in gastric cancer.

\section{Compliance with ethical standards}

Conflict of interest The author declares no conflict of interest in this work.

Research involving human participants and/or animals Not applicable.

Informed consent Not applicable.

\section{References}

1. Shoda K, Ichikawa D, Fujita Y, Masuda K, Hiramoto H, Hamada $\mathrm{J}$, et al. Monitoring the HER2 copy number status in circulating tumor DNA by droplet digital PCR in patients with gastric cancer. Gastric Cancer. 2017;20:126-35.

2. Noguchi T, Wirtz HC, Michaelis S, Gabbert HE, Mueller M. Chromosomal imbalances in gastric cancer. Correlation with histologic subtypes and tumor progression. Am J Clin Pathol. 2001;115:828-34.

3. Page K, Guttery DS, Fernandez-Garcia D, Hills A, Hastings RK, Luo $J$, et al. Next generation sequencing of circulating cell-free DNA for evaluating mutations and gene amplification in metastatic breast cancer. Clin Chem. 2017;63:532-41. doi:10.1373/clinchem. 2016.261834) (Epub ahead of print).

4. Li Y, Zhang X, Ge S, Gao J, Gong J, Lu M, et al. Clinical significance of phenotyping and karyotyping of circulating tumor cells in patients with advanced gastric cancer. Oncotarget. 2014;5:6594-602.

5. Aktas B, Kasimir-Bauer S, Müller V, Janni W, Fehm T, Wallwiener D, et al. Comparison of the HER2, estrogen and progesterone receptor expression profile of primary tumor, metastases and circulating tumor cells in metastatic breast cancer patients. BMC Cancer. 2016;16:522. 